REVIEW ARTICLE

\author{
W.J. van Rooij \\ M. Sluzewski
}

\title{
Endovascular Treatment of Large and Giant Aneurysms
}

SUMMARY: Very large and giant ( $\geq 15 \mathrm{~mm}$ ) cerebral aneurysms have a poor natural history, with high risk of subarachnoid hemorrhage or progressive symptoms of mass effect. Several endovascular techniques may be applied for treatment, depending on location, size, anatomy and presence of collateral circulation. The authors reviewed their clinical experience in endovascular treatment of 232 very large and giant aneurysms and present their perspective on the present state of the art in endovascular therapy for these aneurysms.

$\mathbf{E}$ ndovascular treatment of very large and giant intracranial aneurysms ( $\geq 15 \mathrm{~mm}$ ) has largely replaced surgery during the past decades. Whereas surgery for many of these aneurysms is associated with substantial morbidity, ${ }^{1-3}$ endovascular treatment usually is straightforward with low morbidity. ${ }^{4-7}$ New technical supportive devices such as compliant balloons and easy-to-place intracranial stents have facilitated endovascular treatment of wide-neck aneurysms. ${ }^{8-10}$ In many centers, surgery for large and giant aneurysms is rarely performed. In our practice, endovascular treatment has been the therapy of choice for large and giant aneurysms since 1995. In this review, we want to share our anatomic and clinical results with various endovascular techniques for these aneurysms. On the basis of our own experience and published results of others, we want to express our personal current view about the endovascular treatment of these challenging lesions.

\section{Types of Large Aneurysms}

For the sake of simplicity, very large and giant aneurysms are referred to as "large aneurysms" or just "aneurysms" in this article. Large aneurysms can be classified as ruptured or unruptured. Unruptured aneurysms can be subclassified as symptomatic by mass effect, additional to another symptomatic aneurysm or as an incidental finding. Depending on clinical presentation, the primary goal of endovascular treatment can be prevention of recurrent subarachnoid hemorrhage (SAH), prevention of primary $\mathrm{SAH}$, or alleviation of symptoms of mass effect. The location of large aneurysms can be intradural or extradural in the cavernous sinus. Large aneurysms can be saccular or fusiform. Fusiform aneurysms develop on the basis of intrinsic vessel wall disease; have a separate inflow and outflow tract; and can be dissecting, serpentine, or dolichoectatic. Many large aneurysms contain intraluminal thrombus.

\section{Types of Endovascular Treatment for Large Aneurysms}

Different endovascular treatment strategies may be applied for large aneurysms:

1. Parent vessel occlusion with balloons or coils

2. Selective coil occlusion sparing the parent artery

From the Department of Radiology, St. Elisabeth Ziekenhuis, Tilburg; the Netherlands.

Please address correspondence to W.J. van Rooij, MD, PhD, Department of Radiology, St. Elisabeth Ziekenhuis, Hilvarenbeekseweg 60, 5022 GC Tilburg, the Netherlands; e-mail: radiol@knmg.nl

Indicates open access to non-subscribers at www.ajnr.org

DOI 10.3174/ajnr.A1267
3. Selective coil occlusion with aid of a supporting device (balloon, stent, TriSpan)

4. Selective occlusion with Onyx

5. Parent vessel occlusion after bypass surgery

The choice of the type of endovascular treatment depends on many clinical and anatomic factors such as clinical presentation, aneurysm location, timing of treatment after $\mathrm{SAH}$, the presence of collateral circulation, aneurysm anatomy, and the presence of intraluminal thrombus.

\section{Incidence of Large and Giant Aneurysms with Types of Treatment}

On review of our data base of 1344 endovascularly treated aneurysms since 1995, a total of $232(17.3 \%)$ aneurysms were $15 \mathrm{~mm}$ or larger, and $82(6.1 \%)$ of these were $25 \mathrm{~mm}$ or larger. The location of 232 large and giant aneurysms is displayed in the accompanying Table. The most common location is the carotid artery, especially in the cavernous sinus. In the posterior circulation, the basilar tip is the most frequent location. Of 232 large and giant aneurysms, 134 (58\%) were treated with selective coil occlusion and 98 (42\%) with parent vessel occlusion: 76 were treated with internal carotid artery (ICA) occlusion, 17 with parent artery occlusion in the posterior circulation, and 5 with parent artery occlusion of vessels beyond the circle of Willis. Eight additional patients were referred for bypass surgery, in 4 after incomplete coiling.

\section{Parent Vessel Occlusion}

Parent vessel occlusion, when tolerated, is an appealing technique: it is simple to perform, safe, and definitively excludes the aneurysm from the circulation. Parent vessel occlusion can be performed on the ICA, unilateral or bilateral vertebral artery, proximal basilar trunk, and on intracranial vessels distal to the circle of Willis.

\section{Internal Carotid Artery Occlusion}

ICA occlusion is widely used as therapy for large aneurysms located on the cavernous and ophthalmic segments of the ICA. ${ }^{11-14}$ Also in large aneurysms located distally to the ophthalmic segment (supraclinoid and even ICA bifurcation aneurysms), ICA occlusion can be considered on the condition that the posterior communicating artery is absent and collateral flow is via the anterior communicating artery only. Clinical success of ICA occlusion is mainly dependent on the ability to assess tolerance to permanent occlusion. Historical data from the era of surgical clamp occlusion without previous tolerance testing indicate that approximately $75 \%$ of patients can 


\begin{tabular}{lc}
\hline Location of 232 endovascularly treated large and giant aneurysms \\
\hline Location & Number (\%) \\
\hline Posterior circulation & $80(34)$ \\
Basilar tip & $43(54)$ \\
Posterior inferior cerebellar artery & $11(14)$ \\
Basilar trunk & $10(12)$ \\
Vertebral artery & $7(9)$ \\
Posterior cerebral artery & $5(6)$ \\
Superior cerebellar artery & $4(5)$ \\
Anterior circulation & $152(66)$ \\
Anterior communicating artery & $21(14)$ \\
A2 & $1(0.7)$ \\
Carotid cavernous sinus & $53(35)$ \\
Carotid posterior communicating artery & $17(11)$ \\
Carotid ophthalmic & $16(11)$ \\
Carotid tip & $12(8)$ \\
Carotid hypophyseal & $11(7)$ \\
Carotid supraclinoidal & $9(6)$ \\
Middle cerebral artery & $11(7)$ \\
Pericallosal artery & $1(0.7)$ \\
\hline
\end{tabular}

tolerate ICA occlusion. ${ }^{15}$ Clinical testing during 30 minutes of ICA occlusion in the awake patient identifies patients with immediate ischemia only. To detect patients in whom delayed ischemia will develop (after hours to days), an additional test is required. Such a tolerance test should ideally have a high positive and negative predictive value. Although throughout the years many test occlusion protocols have been developed and, to some extent, validated, in our opinion, supported by other authors, ${ }^{13,16}$ the angiographic test occlusion is the protocol of choice. With this protocol, angiography of the contralateral ICA and/or vertebral artery during ICA balloon test occlusion is used to evaluate circulation times of the tested vascular territory compared with the imaged territory. When cortical veins fill synchronously in both territories, circulation times are equal, which indicates tolerance. If cortical veins in the tested territory fill more than 1 second later than in the imaged territory, tolerance is considered uncertain.

In our experience, the angiographic test has proved very reliable: In 122 ICA test occlusions, angiographic tolerance was present in 86 (70.5\%, close to the expected $75 \%)$, of which 76 were permanently occluded. No early or late permanent neurologic ischemic deficits developed after ICA occlusion in our patient group $(0 \% ; 95 \% \mathrm{CI}, 0.0 \%-4.1 \%)$. The angiographic test has obviated the need for a clinical test in the awake patient and can also be performed in patients under general anesthesia: in our series, in 9 of 76 patients the ICA was permanently occluded with the patients under general anesthesia without a clinical test.

After ICA occlusion, the ICA including the aneurysm thromboses completely; thus, the aneurysm is excluded from the circulation. With time, in most patients the aneurysm shrinks completely or substantially decreases in size, generally within the first year after treatment. In most patients with unruptured aneurysms presenting with mass effect on the cranial nerves, symptoms cure or are relieved soon after therapy. ${ }^{17}$ Although there is some concern about development of de novo aneurysms as a result of hemodynamic alterations in the circle of Willis, we found no such aneurysms on midterm MRA follow-up. There is no reason to believe that patients with ICA occlusion are at higher risk for development of de novo aneurysms than other patients with intracranial aneurysms. ${ }^{18}$

Carotid artery occlusion in the acute phase of SAH cannot be recommended because vasospasm may develop and ischemic events may be aggravated by diminished reserve capacity after occlusion of the carotid artery. In these cases, primary selective coiling may be performed to prevent recurrent rupture, followed by ICA occlusion as a definitive therapy in a later stage.

\section{Vertebral Artery Occlusion}

Large aneurysms located on the intradural V4 segment (between the posterior inferior cerebellar artery (PICA) and vertebral junction), usually caused by dissection, can safely be treated by internal coil trapping. In this way, the whole vertebral segment including the aneurysm is occluded with coils. ${ }^{19}$ The contralateral vertebral artery will provide flow to the basilar artery, and the ipsilateral vertebral artery supplies the PICA. Only in patients with a single vertebral artery without patent posterior communicating arteries, is sparing the parent vessel mandatory. ${ }^{20}$ Although the anterior spinal artery may arise from the V4 segment, this artery is either occluded by previous dissection or its flow will be taken over by cervical contributions to the anterior spinal axis after proximal occlusion during internal coil trapping.

Aneurysms located on the basilar trunk or vertebrobasilar junction in the past have successfully been treated surgically or endovascularly with unilateral or bilateral vertebral occlusion or proximal basilar occlusion. ${ }^{21-23}$ However, with the availability of intracranial stents, these aneurysms can now safely be treated with sparing of the parent vessel, and parent vessel occlusion techniques are hardly ever indicated for these aneurysms. $^{24,25}$

\section{Occlusion of Vessels Beyond the Circle of Willis}

Rarely, large and giant aneurysms are located on vessels distal to the circle of Willis such as on the middle or posterior cerebral artery. Most of these aneurysms are fusiform dissecting, dolichoectatic, or serpentine with circumferential involvement of the vessel wall and a separate inflow and outflow tract. Intraluminal thrombus is often present. As a result of fusiform widening and elongation of the vessel lumen, distal flow may be impaired resulting in development of collateral leptomeningeal circulation. With selective proximal balloon test occlusion of the involved vessel in the awake patient, this leptomeningeal collateral circulation can be tested. If no deficits develop during test occlusion, direct endovascular internal trapping with coils can be considered. ${ }^{26}$ In cases in which test occlusion is not feasible, distal infarction may be anticipated in selected cases, depending on the location of the possible infarction and expected clinical consequences. For example, in a patient with visual field deficit caused by a large posterior cerebral artery dissecting aneurysm, possible distal infarction after internal trapping may have limited effect on the outcome. ${ }^{27}$ Only in exceptional cases, surgical revascularization procedures are required.

\section{Role of Bypass Surgery Preceding Parent Vessel Occlusion} Although bypass surgery is a powerful tool in the treatment of large and giant aneurysms, we find only rarely need for these procedures. Bypass surgery requires exceptional surgical skills 

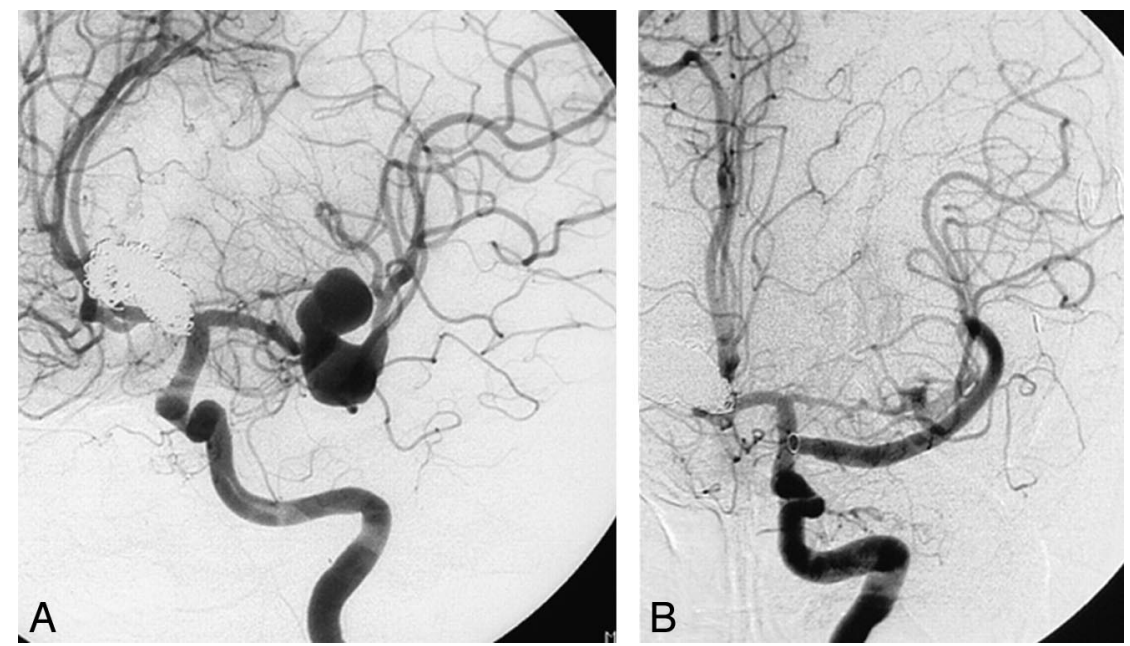

Fig 1. A 46-year-old woman with a coiled ruptured basilar tip aneurysm and an additional large fusiform middle cerebral artery aneurysm. $A$, Fusiform middle cerebral artery aneurysm on the M1-M2 transition. B, Angiogram after construction of an intracranial high-flow bypass from the supraclinoid internal carotid artery to the M2. The aneurysm has completely thrombosed.

and is not available in most neurosurgical centers, including our own. The most appealing technique is high-flow bypass surgery with use of the excimer laser-assisted anastomosis developed by Tulleken. ${ }^{28-30}$ This technique has the advantage of not involving temporary occlusion of the donor or recipient vessel with inherent risks of inducing ischemia. However, although this technique has evolved during the last decades, serious complications are not uncommon: In a study by Brilstra et al, ${ }^{30}$ short-term outcomes of this technique in 77 patients were evaluated. In 10 (13\%) of 77 patients, operative complications resulted in dependency ${ }^{7}$ or death. ${ }^{3}$ Therefore, this technique should be primarily reserved for patients with intradurally located large or giant aneurysms with high chance of rerupture who cannot tolerate parent artery occlusion and cannot be treated with selective endovascular techniques (Fig 1).

\section{Selective Endovascular Treatment of Large and Giant Aneurysms}

Selective endovascular occlusion of large and giant aneurysms with sparing of the parent vessel can be achieved by filling the aneurysm lumen with detachable coils or the liquid embolic agent Onyx. In patients who cannot tolerate parent vessel occlusion, selective endovascular treatment is a valuable alternative.

\section{Selective Coiling of Large and Giant Aneurysms}

Selective coiling of large and giant aneurysms differs in several aspects from coiling of small aneurysms. Because most large aneurysms have a wide neck, supporting devices (balloon, stent, TriSpan) are often needed. With time, most aneurysms reopen by coil compaction, coil migration into intraluminal thrombus, or dissolution of intraluminal thrombus resulting in luminal enlargement. ${ }^{6,7,31}$ Why is coil compaction so frequent in large aneurysms? From studies concerning packing attenuation (inserted coil volume/aneurysm volume) we know that most aneurysms packed for approximately $25 \%$ or more remain stable at follow-up. ${ }^{32}$ With less packing, reopening is more frequent. Empiric data show that the larger the aneurysm volume, the less packing can be achieved. Although on radiographic examination the aneurysm may seem tightly packed with coils and completely occluded (Fig 2), calculation of packing attenuation often proves disappointing. For example, in a $24-\mathrm{mm}$ spherical aneurysm (volume, $7233 \mathrm{~mm}^{3}$ ), when 20 Guglielmi detachable 18 coils (Boston Scientific) of $30 \mathrm{~cm}$ (total length, $600 \mathrm{~cm}$; volume, $684 \mathrm{~mm}^{3}$ ) are inserted, the aneurysm may seem adequately occluded, but packing is only $9.5 \%$ and compaction is likely to occur. Despite the use of thick, soft, or complex-shaped bare platinum coils, high packing densities can hardly be achieved in large and giant aneurysms. In our practice, we consider selective coiling of large and giant aneurysms as a staged treatment with ongoing follow-up and additional coiling when necessary. With first coiling, we confine our efforts to occlude the neck at the end of the procedure to a minimum because reopening at the neck is likely to occur later. We prefer using a supporting balloon above a stent when neck support is needed because with stentassisted treatment, prolonged antiplatelet medication is necessary.

\section{Selective Treatment of Large and Giant Aneurysms with Onyx}

Recently, filling the aneurysm lumen with Onyx has been proposed as a treatment for aneurysms with sparing of the parent artery. ${ }^{33,34}$ With this treatment, the neck of the aneurysm is sealed with a balloon during Onyx injection. The need for prolonged balloon inflation practically limits indication to ICA aneurysms. In a multicenter study by Molyneux, ${ }^{33}$ permanent neurologic morbidity was $8.3 \%$ (8/97 patients) with 2 procedural deaths. In large and giant aneurysms, procedural time was long (up to 6 hours). Delayed occlusion of the carotid artery occurred in 9 (9\%) of 100 patients. At 12 months' follow-up of 53 patients, 38 (72\%) large and giant aneurysms were completely occluded. Retreatment was performed in 9 (11\%) of 79 . Although some single-center studies show slightly better results, in our opinion, the relatively high complication rate and high rate of delayed carotid artery occlusion do not justify this treatment in patients with unruptured aneurysms who cannot tolerate carotid artery occlusion. The technique of sealing the neck during Onyx injection requires new skills and judgment for most operators with an inevitable 

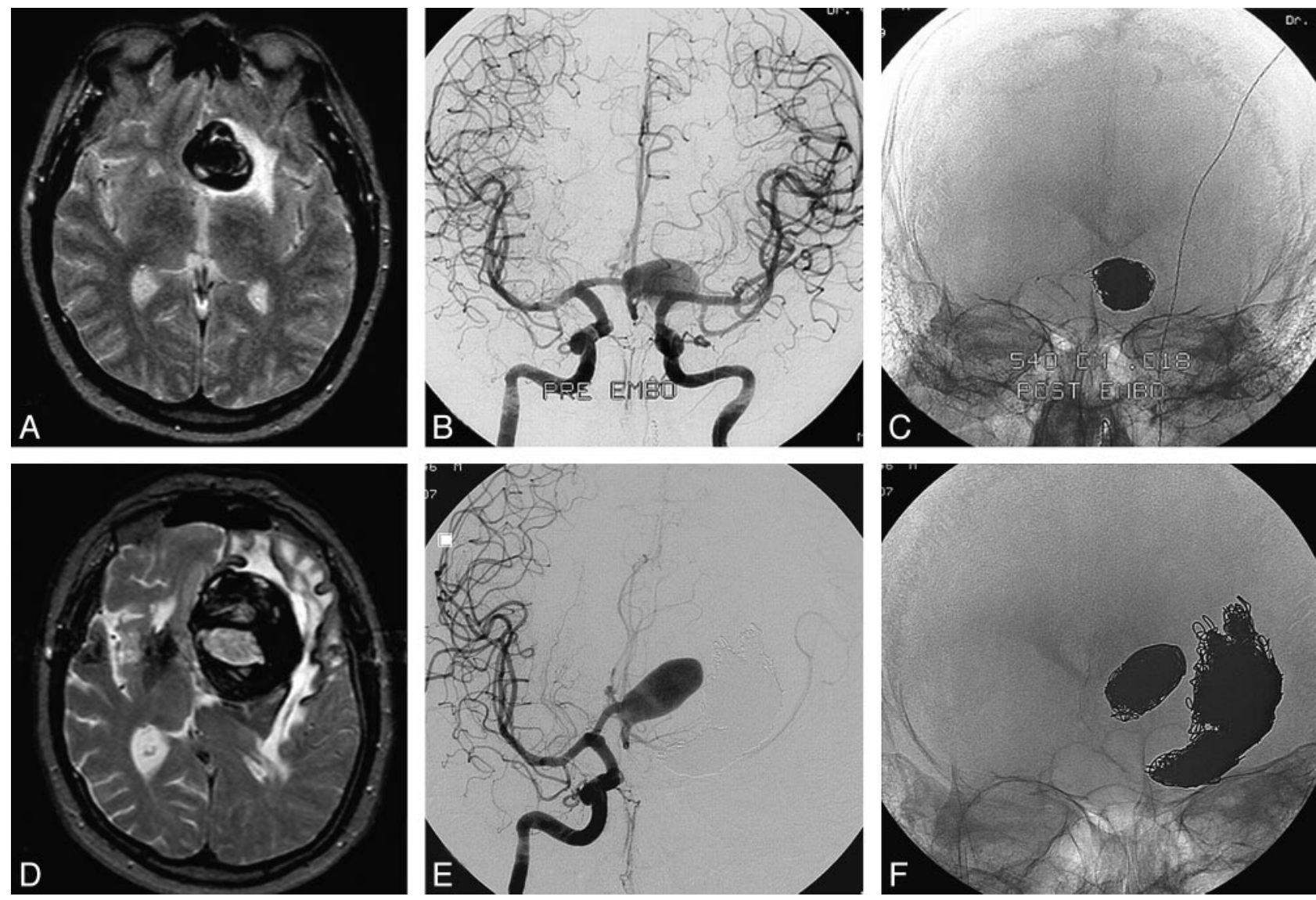

Fig 2. A 52-year-old man presenting with frontal syndrome. $A, M R$ imaging reveals a partially thrombosed anterior communicating artery aneurysm with surrounding edema. $B$ and $C$, Angiogram showing aneurysmal lumen and coil mesh after coiling. $D$ and $E$, MR imaging $(D)$ and angiogram $(E) 8$ years and 4 coiling procedures later: the aneurysm has enlarged with increased mass effect and edema. There is progressive frontal syndrome. F, Radiograph after fifth coiling. Note migration of previous coils into intraluminal thrombus. During 5 coiling procedures, $2970 \mathrm{~cm}$ of 0.018 coils were inserted.

learning curve. As for now, short-term results of Onyx occlusion for large aneurysms are not better than for selective coil occlusion, and the immediate and delayed complication rate is probably higher.

\section{Follow-up of Large and Giant Aneurysms after Treatment}

After parent vessel occlusion, imaging follow-up can be limited to short-term follow-up MR imaging to confirm thrombosis of the aneurysm and evaluate possible distal ischemic lesions.

After selective coiling, angiographic or MR imaging follow-up is mandatory because reopening is frequent. In our practice, we perform first follow-up after 3 months in partially thrombosed aneurysms and after 6 months in aneurysms without intraluminal thrombus. Almost all coiled large and giant aneurysms show some reopening: if reopening is confined to the neck, we schedule the next follow-up 6 months later and yearly thereafter. If reopening results in partial aneurysm filling, we perform additional coiling when necessary with balloon or stent assistance. Additional coiling has a low complication rate ${ }^{35}$; in many repeated procedures, we never encountered a serious complication. After every additional coiling, follow-up is scheduled as after first coiling. Before first coiling, we explain this follow-up strategy to the patients. Although we stress the importance, some patients decline follow-up imaging at later intervals, especially when the occlu- sion status of the aneurysm is stable during several years. Since we started coiling in 1994, the number of patients with coiled large and giant aneurysms with follow-up of more than 5 and even 10 years is steadily growing. In the last years, we noticed that selective coiling of large and giant aneurysms does not always prevent continuous growth of the aneurysm with sometimes devastating consequences (Fig 2). In the 5- to 10year interval after selective coiling (followed by additional coiling in many patients), sudden and unexpected rapid reopening and regrowth may occur with possible aneurysmal rupture or increased mass effect (Figs 3 and 4). ${ }^{31,36}$ This late growth and reopening, even after a stable situation during some years, particularly seems to occur in partially thrombosed bifurcation-type aneurysms such as on the basilar tip and, so far, not yet in sidewall aneurysms on the carotid artery. Growing basilar tip aneurysms cause life-threatening mass effect on the brain stem. Although the frequency of these observations is not yet known, we are more and more convinced of the importance of life-long yearly imaging follow-up in all patients with coiled large and giant aneurysms.

\section{Clinical Outcome of Endovascular Treatment of Large and Giant Aneurysms}

Clinical outcome after endovascular treatment is dependent on several factors: clinical presentation, procedural complica- 

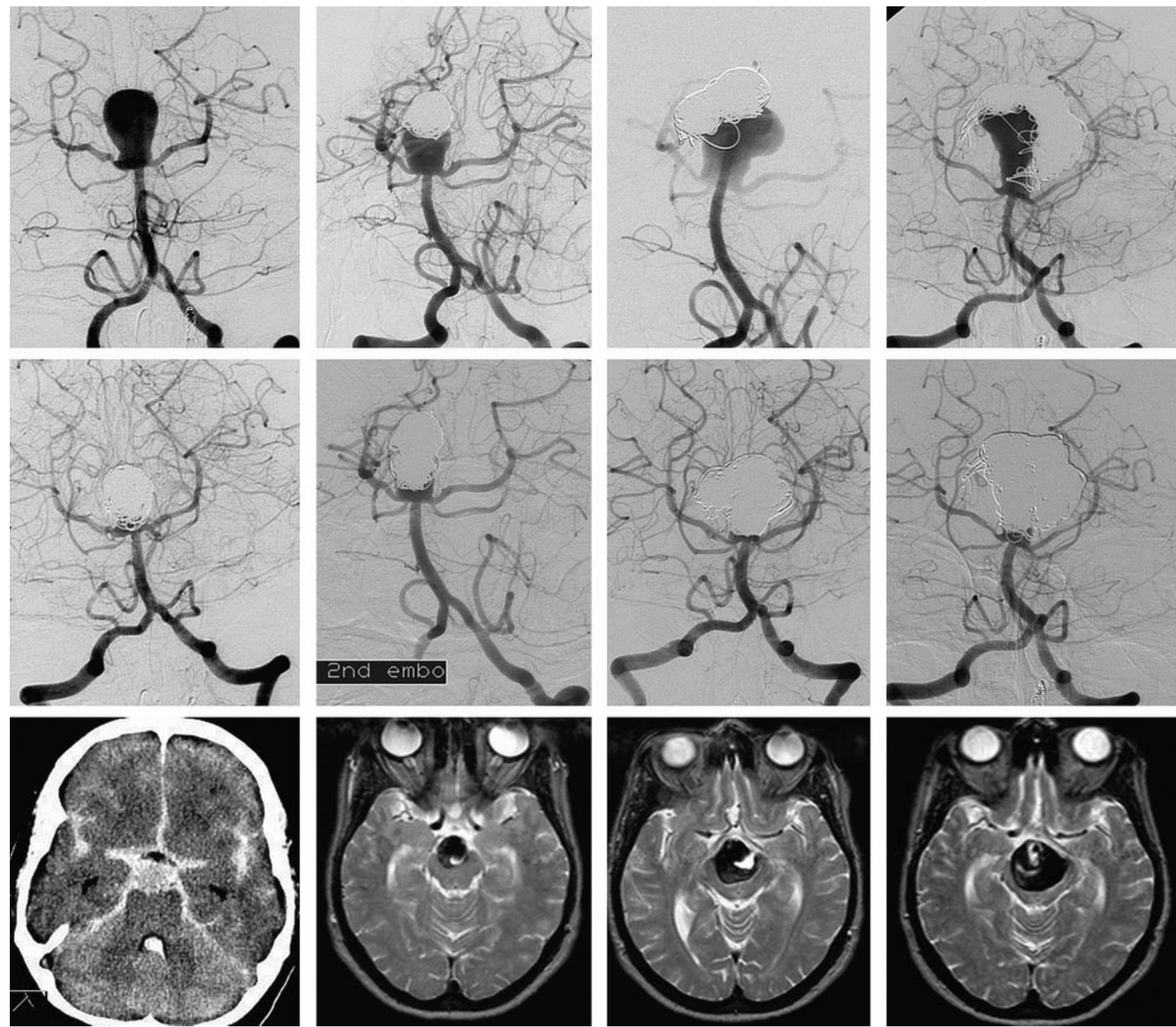

Fig 3. A 44-year-old woman with coiled ruptured basilar tip aneurysm with repeated reopening and progressive growth during 6 years' time. Upper-row images show basilar tip aneurysm at presentation and before second, third, and fourth coiling at 1, 3, and 6 years. Middle-row images show corresponding results of coiling procedures, and lower-row images demonstrate increased mass effect on the brain stem at corresponding intervals. The patient is still asymptomatic.
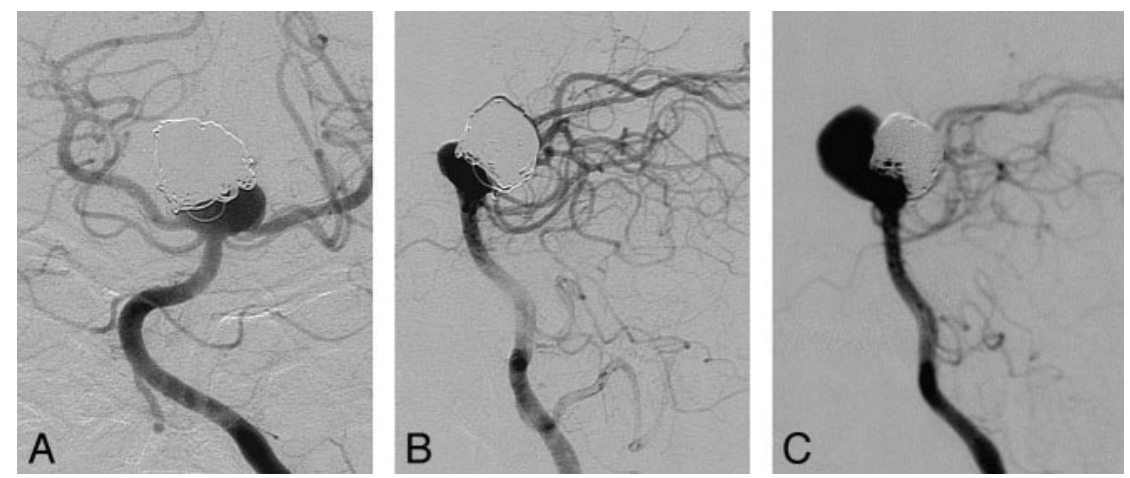

Fig 4. A 38-year-old man with ruptured basilar tip aneurysm with late regrowth and recurrent hemorrhage. $A$ and $B$, Angiogram 8 years after first coiling demonstrates reopening at the neck that had slowly progressed during the years. Additional treatment was judged difficult. $C$, Angiogram after recurrent hemorrhage 10 years after first coiling. Note rapid enlargement and reopening of the aneurysm in the 8- to 10-year interval. The aneurysm was additionally coiled, and the patient made an uneventful recovery

tions, and effectiveness of treatment in both the short and long term.

In patients with ruptured large and giant aneurysms, pre- vention of short-term recurrent hemorrhage is the primary goal of treatment. For ruptured intradural carotid artery aneurysms in patients in poor clinical condition, primary coiling 
(even aimed at partial occlusion) usually is effective to prevent recurrent hemorrhage. In a later stage, after the vasospasm period, more definitive treatment such as carotid artery occlusion or surgery can be considered. For ruptured large aneurysms at other locations, parent vessel occlusion, when tolerated, is the therapy of choice. Even when tolerance is uncertain, infarction in the territory of the occluded vessel may be anticipated in the light of already present clinical symptoms (eg, in ruptured distal dissecting aneurysms).

For large unruptured aneurysms that are incidentally discovered or present with mass effect on the cranial nerves, parent vessel occlusion is the most appropriate therapy because it is safe, effective, and definitive. When parent vessel occlusion is not tolerated, selective coiling is a valuable low-risk alternative with equally favorable short-term outcome on symptoms of mass effect compared with parent vessel occlusion. ${ }^{37,38}$ When neck support is indispensable, a balloon is preferred to a stent because after stent placement, prolonged antiplatelet therapy is required. Selective occlusion with Onyx has no advantages to selective coil occlusion, and the complication rate is higher.

After selective coiling, prolonged imaging follow-up at regular intervals is mandatory because early reopening is frequent. New data indicate that selective coiling does not always protect against continuous growth of the aneurysm in the next 10 years, resulting in increasing mass effect and risk for recurrent hemorrhage. More long-term follow-up data of coiled large and giant aneurysms are needed to assess the frequency of this phenomenon.

\section{Summary Statements}

1. Parent vessel occlusion, when tolerated, is the endovascular therapy of choice for all large and giant aneurysms, with the exception of basilar trunk aneurysms. Parent vessel occlusion is safe, effective, and definitive, and prolonged imaging follow-up is not needed. Most aneurysms shrink with time, with favorable outcome on symptoms of mass effect. Tolerance to carotid artery occlusion can be reliably evaluated with angiographic testing, even in patients under general anesthesia. Clinical balloon test occlusion can be performed in vessels beyond the circle of Willis.

2. When parent vessel occlusion is not tolerated, selective coiling is a low-risk alternative. Selective coiling offers protection against recurrent hemorrhage, and short-term outcome of symptoms of mass effect is usually good. Wideneck aneurysms can be coiled with assistance of a balloon or stent. Because reopening with time frequently occurs, follow-up imaging is mandatory. Additional coiling has a low complication rate and should be performed when necessary. Late aneurysm regrowth and reopening may occur, even after stable occlusion during some years, particularly in large basilar tip aneurysms.

3. Selective aneurysm occlusion with Onyx offers no advantages to selective coiling, and the complication rate is probably higher with a risk for delayed parent vessel occlusion.

4. Bypass surgery preceding parent vessel occlusion can be effective in intradurally located aneurysms that cannot be treated otherwise, but it is only rarely needed.

\section{References}

1. Lozier AP, Kim GH, Sciacca RR, et al. Microsurgical treatment of basilar apex aneurysms: perioperative and long-term clinical outcome. Neurosurgery 2004;54:286-96

2. Sullivan BJ, Sekhar LN, Duong DH, et al. Profound hypothermia and circulatory arrest with skull base approaches for treatment of complex posterior circulation aneurysms. Acta Neurochir (Wien) 1999;141:1-11

3. Ogilvy CS, Carter BS. Stratification of outcome for surgically treated unruptured intracranial aneurysms. Neurosurgery 2003;52:82-87

4. Lempert TE, Malek AM, Halbach VV, et al. Endovascular treatment of ruptured posterior circulation cerebral aneurysms. Clinical and angiographic outcomes. Stroke 2000;31:100

5. Lozier AP, Connolly ES Jr, Lavine SD, et al. Guglielmi detachable coil embolization of posterior circulation aneurysms: a systematic review of the literature. Stroke 2002;33:2509-18

6. Sluzewski M, Menovsky T, van Rooij WJ, et al. Coiling of very large or giant cerebral aneurysms: long-term clinical and serial angiographic results. AJNR Am J Neuroradiol 2003;24:257-62

7. Gruber A, Killer M, Bavinzski G, et al. Clinical and angiographic results of endosaccular coiling treatment of giant and very large intracranial aneurysms: a 7-year, single-center experience. Neurosurgery 1999;45:793-803

8. Sluzewski M, van Rooij WJ, Beute GN, et al. Balloon-assisted coil embolization of intracranial aneurysms: incidence, complications, and angiography results. J Neurosurg 2006;105:396-99

9. Kessler IM, Mounayer C, Piotin M, et al. The use of balloon-expandable stents in the management of intracranial arterial diseases: a 5-year single-center experience. AJNR Am J Neuroradiol 2005;26:2342-48

10. Kis B, Weber W, Berlit P, et al. Elective treatment of saccular and broad-necked intracranial aneurysms using a closed-cell nitinol stent (Leo). Neurosurgery 2006;58:443-50

11. van der Schaaf IC, Brilstra EH, Buskens E, et al. Endovascular treatment of aneurysms in the cavernous sinus: a systematic review on balloon occlusion of the parent vessel and embolization with coils. Stroke 2002;33:313-38

12. Larson JJ, Tew JM Jr, Tomsick TA, et al. Treatment of aneurysms of the internal carotid artery by intravascular balloon occlusion: long-term follow-up of 58 patients. Neurosurgery 1990;36:23-30

13. van Rooij WJ, Sluzewski M, Slob MJ, et al. Predictive value of angiographic testing for tolerance to therapeutic occlusion of the carotid artery. AJNR Am J Neuroradiol 2005;1:175-78

14. Lubicz B, Gauvrit JY, Leclerc X, et al. Giant aneurysms of the internal carotid artery: endovascular treatment and long-term follow-up. Neuroradiology 2003;45:650-55

15. Linskey ME, Jungreis CA, Yonas $\mathrm{H}$, et al. Stroke risk after abrupt interna carotid artery sacrifice: accuracy of preoperative assessment with balloon test occlusion and stable xenon-enhanced CT. AJNR Am J Neuroradiol 1994;15:829-43

16. Abud DG, Spelle L, Piotin M, et al. Venous phase timing during balloon test occlusion as a criterion for permanent internal carotid artery sacrifice. AJNR Am J Neuroradiol 2005;26:2602-09

17. de Gast AN, Sprengers ME, van Rooij WJ, et al. Midterm clinical and magnetic resonance imaging follow-up of large and giant carotid artery aneurysms after therapeutic carotid artery occlusion. Neurosurgery 2007;60:1025-29

18. de Gast AN, Sprengers ME, van Rooij WJ, et al. Long term 3T-MRA follow-up after therapeutic occlusion of the internal carotid artery to detect possible de novo aneurysm formation. AJNR Am J Neuroradiol 2007;28:508-10

19. Peluso JP, van Rooij WJ, Sluzewski M, et al. Endovascular treatment of symptomatic intradural vertebral dissecting aneurysms. AJNR Am J Neuroradiol 2008;29:102-06

20. Sluzewski M, Brilstra EH, van Rooij WJ, et al. Bilateral vertebral artery balloon occlusion for giant vertebrobasilar aneurysms. Neuroradiology 2001;43:336-41

21. Steinberg GK, Drake CG, Peerless SJ. Deliberate basilar or vertebral artery occlusion in the treatment of intracranial aneurysms. Immediate results and long-term outcome in 201 patients. J Neurosurg 1993;79:161-73

22. Fox AJ, Viñuela F, Pelz DM, et al. Use of detachable balloons for proximal artery occlusion in the treatment of unclippable cerebral aneurysms. J Neuro$\operatorname{surg} 1987 ; 66: 40-46$

23. Peluso JP, van Rooij WJ, Sluzewski M, et al. Aneurysms of the vertebrobasilar junction: incidence, clinical presentation, and outcome of endovascular treatment. AJNR Am J Neuroradiol 2007;28:1747-51

24. Fiorella D, Woo H, Albuquerque F, et al. Definitive reconstruction of circumferential, fusiform intracranial aneurysms with the pipeline embolization device. Neurosurgery 2008;62:1115-20; discussion 1120-21

25. Nelson PK, Sahlein D, Shapiro M, et al. Recent steps toward a reconstructive endovascular solution for the orphaned, complex-neck aneurysm. Neurosurgery 2006;59 Suppl:77-92 
26. van Rooij WJ, Sluzewski M, Beute GN. Endovascular treatment of giant serpentine aneurysms. AJNR Am J Neuroradiol 2008;29:1418-19. Epub 2008 Apr 3.

27. van Rooij WJ, Sluzewski M, Beute GN. Endovascular treatment of posterior cerebral artery aneurysms. AJNR Am J Neuroradiol 2006;27:300-05

28. Bremmer JP, Verweij BH, Van der Zwan A, et al. Sutureless nonocclusive bypass surgery in combination with an expanded polytetrafluoroethylene graft. Laboratory investigation. J Neurosurg 2007;107:1190-97

29. Langer DJ, Van Der Zwan A, Vajkoczy P, et al. Excimer laser-assisted nonocclusive anastomosis. An emerging technology for use in the creation of intracranial-intracranial and extracranial-intracranial cerebral bypass. Neurosurg Focus 2008;24:E6

30. Brilstra EH, Rinkel GJ, Klijn CJ, et al. Excimer laser-assisted bypass in aneurysm treatment: short-term outcomes. J Neurosurg 2002;97:1029-35

31. van Rooij WJ, Sluzewski M. Coiling of very large and giant basilar tip aneurysms: midterm clinical and angiographic results. AJNR Am J Neuroradiol 2007;28:1405-08

32. Sluzewski M, van Rooij WJ, Slob MJ, et al. Relation between aneurysm volume, packing, and compaction in $\mathbf{1 4 5}$ cerebral aneurysms treated with coils. Radiology 2004;231:653-58
33. Molyneux AJ, Cekirge S, Saatci I, et al. Cerebral Aneurysm Multicenter European Onyx (CAMEO) trial: results of a prospective observational study in 20 European centers. AJNR Am J Neuroradiol 2004;25:39-51

34. Weber W, Siekmann R, Kis B, et al. Treatment and follow-up of 22 unruptured wide-necked intracranial aneurysms of the internal carotid artery with Onyx HD 500. AJNR Am J Neuroradiol 2005;26:1909-15

35. Slob MJ, Sluzewski M, van Rooij WJ, et al. Additional coiling of previously coiled cerebral aneurysms: clinical and angiographic results. AJNR Am J Neuroradiol 2004;25:1373-76

36. van Rooij WJ, Sprengers ME, Sluzewski M, et al. Intracranial aneurysms that repeatedly reopen over time after coiling: imaging characteristics and treatment outcome. Neuroradiology 2007;49:343-49

37. van Rooij WJ, Sluzewski M. Unruptured large and giant carotid artery aneurysms presenting with cranial nerve palsy: comparison of clinical recovery after selective aneurysm coiling and therapeutic carotid artery occlusion. AJNR Am J Neuroradiol 2008;29:997-1002.

38. Mansour N, Kamel MH, Kelleher M, et al. Resolution of cranial nerve paresis after endovascular management of cerebral aneurysms. Surg Neurol 2007;68: $500-04$ 